\title{
Frequency response analysis for transformer tap changer damage detection
}

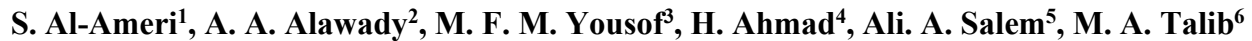 \\ 1,2,3,4,5 Department of Electrical \& Electronics Engineering, Universiti Tun Hussein Onn Malaysia, Malaysia \\ ${ }^{2}$ Department of Computer Technical Engineering, College of Technical Engineering Islamic University, Iraq \\ ${ }^{6}$ Tenaga Nasional Berhad Research, Malaysia
}

\begin{tabular}{l}
\hline \hline Article Info \\
\hline Article history: \\
Received Aug 7, 2019 \\
Revised Oct 27, 2019 \\
Accepted Nov 13, 2019 \\
\hline
\end{tabular}

Keywords:

Coking

Frequency response analysia

Pitting

Tap changer fault

Transformer turn ratio

\begin{abstract}
Frequency response analysis (FRA) method has been proven to detect the transformer winding damage. However, there is no practical study which investigates the damages on transformer tap changer even though it has a high failure rate. Hence, this paper investigates normal and faulty transformer tap changer using FRA. The FRA measurements conducted using four different test configurations. Also, normal tap changer, pitting and coking tap changer contact were investigated. In addition to FRA measurement, winding resistance measurement has been conducted. The transformer turn ratio measurement also conducted to identify the taps positions. This study results significant to understand the effect of pitting and coking tap changer on the transformer frequency response. The results showed that pitting has a slight influence on the frequency response. However, coking shows a huge variation in low-frequency response. This effect observed during the winding resistance measurement.
\end{abstract}

This is an open access article under the CC BY-SA license.

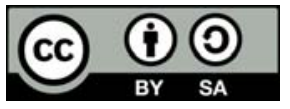

\section{Corresponding Author:}

Salem Mgammal Awadh Nasser Al-Ameri

Departement of Electrical and Electronics Engineering,

University Tun Hussein Onn Malaysia,

Parit Raja, 86400, Malaysia.

Email: mgammal10@gmail.com

\section{INTRODUCTION}

Transformers are used in the transmission and distribution systems to step up and down the voltages. During operational lifetime, transformers are exposed to failures. These failures could be due to overloaded, earthquake, and mishandle during transportation. Other examples are transformer winding deformation, insulation degradation, and transformer bushings. Statistical studies reported by CIGRE presented that tap changer has the highest percentage $56 \%$ of the transformer failures [1].

In order to investigate the transformer tap changer failure, there are few methods such as dynamic resistance measurement (DRM) $[2,3]$. The previous papers in using DRM for tap changer diagnosis did not provide an explanation on the effect of various of failures on the frequency response [2, 4]. The contact problems in the DETC could be investigated using winding resistance measurement and excitation current measurement $[5,6]$. These two methods considered as a conventional test. On the other hand, frequency response analysis (FRA) considered as a modern method. Also, there is a general agreement that FRA is sensitive to the mechanical changes within the transformer [7,8]. There are several studies in order to investigate the transformer tap changer faults using FRA. The influence of tap changer on FRA is investigated. However, this study only varying the tap changer setup [9]. Also, S. Banaszak in [10], the paper presented a study on the influence of tap changer position on the FRA. Reference [11] investigate the effect 
of faulty tap changer on FRA measurement. However, this study investigates the faulty tap changer based on single phase transformer. The study also examines faulty tap changer using open circuit test only.

This paper investigates the effect of faulty tap changer on a three-phase distribution transformer using FRA. The three-phase distribution transformer is located at a local power utility research center. It is $11 / 0.433 \mathrm{kV}$ and rated at 500kVA. There are three tap changer conditions investigated in this paper which are normal, pitting and coking tap changer contact. The measurement is conducted based on an end to end open circuit, an end to end short circuit, capacitive inter-winding, and inductive inter-winding tests. This study verifies the transformer winding in healthy condition using turn ratio test and winding resistance test. The significance of this study shows the capability of FRA to detect the faulty transformer tap changer. In addition, it is to improve the inspection and interpretation of the transformer failures.

\section{FREQUENCY RESPONSE ANALYSIS}

Frequency response analysis is a well-used technique to diagnosis mechanical changes in the transformer winding $[12,13]$. Basically, the main function of FRA is to determine the damage on the active parts of the transformer (winding, leads, and core). Also, it has been reported that FRA can detect nonmechanical changes such as temperature and moisture content of winding insulation. FRA is a comperhinsive technique to assess the transformer condition [14]. FRA is a comparative test which required reference data to compare with. Therefore, any differences between the two measurement response suggested there is fault $[8,15]$. The FRA measurement is conducted by applying a small sinusoidal AC voltage signal at different frequencies. This signal is injected at one end of the transformer winding and measured the output signal at the other end of the winding as shown in Figure 1. The ratio between the measured and the injected signals is called the transfer function. The transfer function carries information regarding the capacitance, resistance, mutual inductance, inductance, of the winding and core. Therefore, changes in the transformer winding and core will alter its transfer function. The transfer function will show these changes in the amplitude and phase of the measured signal [16].

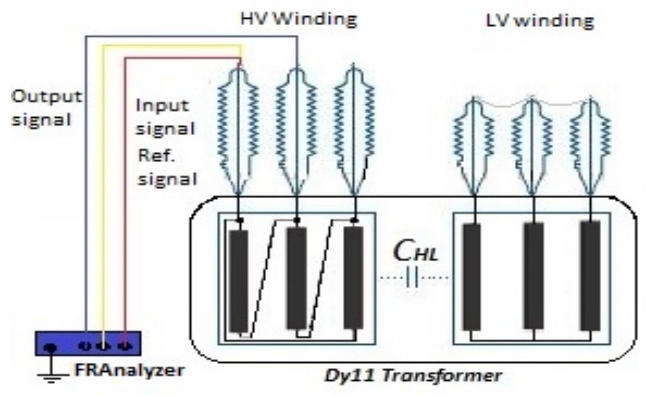

Figure 1. The measurement configuration for the tested transformer [5]

There are four measurement connections between the transformer and FRA equipment. These are end to end open circuit, end to end short circuit, capacitive inter-winding, and inductive inter-winding [15]. The FRA instrument can obtain the voltage transfer function of the winding from $20 \mathrm{~Hz}$ to $2 \mathrm{MHz}$. This frequency range is then divided into sub-bands in order to interpret the FRA results. These sub-bands are different from one transformer to another. The FRA sub-bands depend on the size of the transformer, type and arrangement. In literature, there are several statistical methods proposed to interpret the FRA measurement. For example, the correlation coefficient (CC) in $[17,18]$, the absolute sum of logarithmic error (ASLE) $[19,20]$.

\section{TAP CHANGER FAULTS}

A statistical study on transformer failures was conducted in [1]. It indicated that tap changer fault occupies the highest percentage in power transformer failures. It was reported by CIGRE that $56 \%$ of power transformer faults in the Netherlands were caused by tap changer. Hence, the study of fault on power transformer tap changer is a major concern in recent years [21]. There are three OLTCs contact degradation stages accrued. These are film on the contact surface, high local temperature (coking) on the contact surface and finally contact failure due to overheating (pitted spots or pitting). Other failures can occur such as 
chemical or mechanical wear, for instance, oxidation, coking, mechanical wear, fretting and thermal deformations (pitting) [22].

\subsection{Coking}

Coking is a chemical process when carbon is extracted from the surrounding oil of power transformer and attached on the tap changer contact. The process started with thin oil film formation on the contact. Subsequently, it leads to increasing of tap contact resistance. Therefore, it produces more heat. Moreover, this phenomenon activates when temperature close to $200{ }^{\circ} \mathrm{C}$ above. Then, the surrounding oil will form coking on tap changer contact [22]. Based on the previous study in literature coking influence the contact resistance and higher its temperature [11,23].

\subsection{Pitting}

Pitting corrosion is localized small cavities or holes formed in metals such as copper. Typically, pitting accrued in the advanced stages of aging and on the change over selector contacts [4]. Besides of the increase of carbon, small pitted spots are created which can be developed into deep holes.

\section{METHODOLOGY}

\subsection{Transformer configuration}

This experimental study is conducted on a three-phase distribution transformer with de-energized tap changer (DETC) rated at 11/0.433 kV, $500 \mathrm{kVA}$ as shown in Figure 2(a). The transformer vector group and configuration also are shown in Figure 2(b). The winding taps are connected to the tap changer selector as shown in Figure 2(c). Tap changer setting is provided in Table 1. It briefly explains the tap changer numbers and the taps winding connected. For example, Tap 1 connects tap number 4 and 5 thus, selecting the whole winding while Tap 5 connects tap number 2 and 7 which only selects the minimum amount of turn in the winding. However, in this transformer, the taps numbers are not marked in the tap changer selector. This is because the transformer has been un-tanked before and the tap leads have been removed. For this reason, turns ratio test need to be performed to identify the taps numbers.

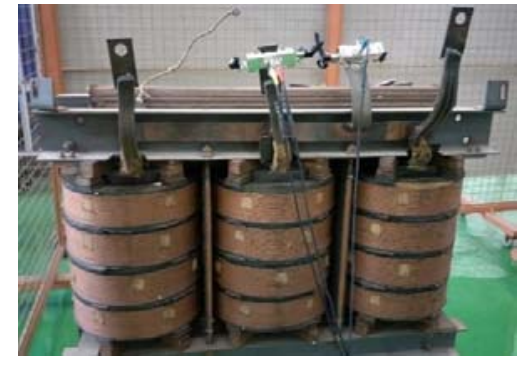

(a)

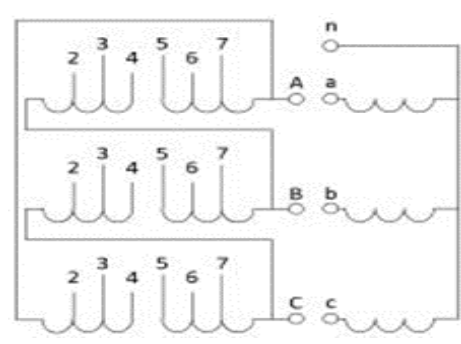

(b)

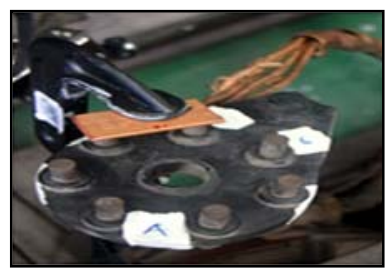

(c)

Figure 2. (a) Experimented 500kVA distribution transformer (b) transformer winding configuration (c) tap changer selector DETC position control

\subsection{Transformer turn ratio measurement}

Turn ratio test is conducted for all transformer taps. It is to indicate the Vratio for all taps. This measurement will help to identify the taps numbers which are not marked in the tap changer selector. It is also to validate the condition of all three phases winding. This is by comparing the measured and calculated Vratio. It has a simple connection where the input signal injected at HV terminal and the output signal measured at the LV side. The turn ratio test was conducted using TRF-100 which is manufactured by Vanguard Instrument. To calculate the turn ratio from the transformer nameplate:

$$
V_{\text {ratio }}=\frac{H V_{\text {phase }}}{L V_{\text {phase }}}
$$


In a delta connection, $\mathrm{V}_{\text {line }}=\mathrm{V}_{\text {phase}}$, however, to get $\mathrm{V}_{\text {line }}$ in star connection $\mathrm{V}_{\text {line }}=\mathrm{V}_{\text {phase }} \times \sqrt{ } 3$. The TRF-100 also calculate the percentage difference $(\Delta \%)$ between the calculated and measured voltage ratio.

\subsection{Tap changer faults fabrication}

Copper tape is used to investigate the effect of faulty tap changer on FRA measurement. The most common tap changer failures are coking and pitting. To perform coking, charcoal dust has been glued on a piece of copper tape. Basically, the glue applied on the copper surface did not affect the contact because it has been dried before using. On the other hand, to form pitting corrosion on the copper tape, hammer and chisel were used. The normal, coking and pitting copper tape are shown in Figure 3 . The copper tapes are used to connect two taps in DETC by holding using G-clamp as shown in

Figure 2(c).

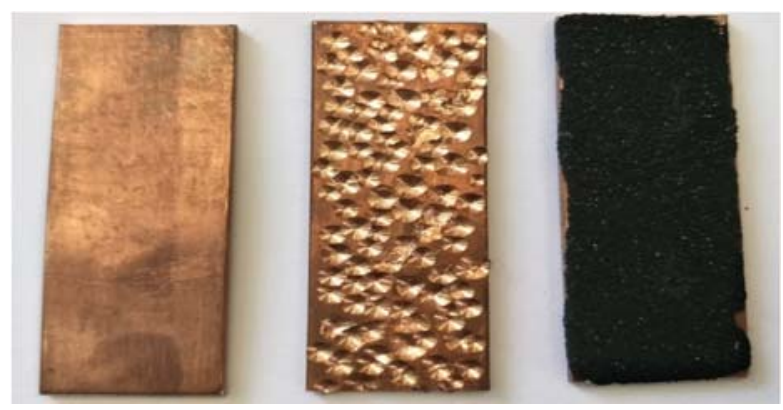

Figure 3. The fabricated copper tapes. From left, normal, pitting and coking.

\subsection{FRA measurement connection}

According to CIGRE WG A2.26 [15], IEEE C57.146 standard [8] and IEC 60076-18 [24] there are four measurement configurations between the transformer and FRA equipment. They are end to end open circuit, end to end short circuit, capacitive inter-winding, and inductive inter-winding. In the end to end open circuit, the signal is injected at one end of the winding and measure the output signal at another end of the same winding while the low voltage winding is open. The end to end short circuit measurement is similar to end to end open circuit but the low voltage winding terminals are shorted. The capacitive inter-winding connection is conducted by applying the input signal at the high voltage side and measure the output voltage at the low voltage side. The inductive inter-winding connection is quite similar to capacitive inter-winding, but the high voltage and low voltage windings are grounded.

\subsection{Winding resistance measurement}

The winding resistance measurement is conducted to determine the winding resistance value. It is believed that coking in tap changer increases the total winding resistance. Hence, the winding resistance measurement is performed. This measurement could support the FRA measurement. The winding resistance meter is a digital resistance reading from 1 micro-ohm to $500 \mathrm{ohms}$ [25]. Winding resistance measurement is conducted at $\mathrm{HV}$ side of one phase.

\section{RESULTS AND ANALYSIS}

It was mentioned earlier that transformer turn ratio measurement is conducted to determine the taps positions. There are five taps in the HV winding but they are not marked. Transformer turn ratio was performed to validate if the voltage ratio of all phases is in good condition. Table 1 shows the calculated voltage ratio. From the results of voltage ratio and current values, we can determine the actual configuration of the transformer winding and tap changer position. The actual arrangement is shown in Figure 4(a) and Figure 4(b). Hence the new arrangement can be summarised in Table 1. Further investigation on the condition of all phase's voltage ratio is performed using (2). Here TRC and TRM are the calculated and the measured turn ratio respectively. The deviation in voltage ratio and action is proposed by local power utility and given in Table 2. The calculation identifies that all phases are in good condition and the results are shown in Table 3. 


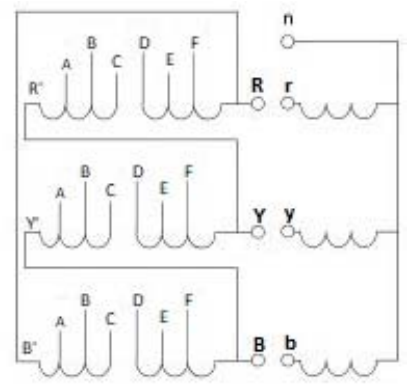

(a)

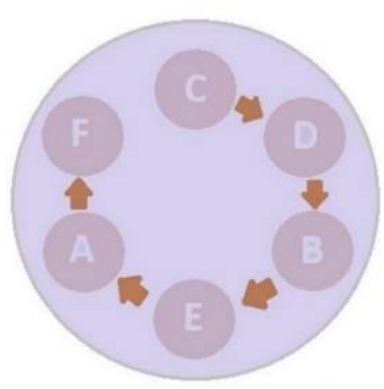

(b)

Figure 4. The Dyn1 1 transformer winding configuration (a) the new arrangement (b) right inset is the new schematic arrangements

Table 1. The tap connection from nameplate and calculated vratio

\begin{tabular}{llllll}
\hline Tap & HV rating & \multicolumn{2}{l}{ Tap connection } & LV rating & $\mathrm{V}_{\text {ratio }}$ Calculated \\
\hline 1 & 11550 & $4-5$ & C-D & & 46.201 \\
2 & 11275 & $5-3$ & D-B & & 45.101 \\
3 & 11000 & $3-6$ & B-E & 433 & 44.001 \\
4 & 10725 & $6-2$ & E-A & & 42.901 \\
5 & 10450 & $2-7$ & A-F & & 41.801 \\
\hline
\end{tabular}

Table 2. Result and actions for turn ratio test of phase's deviations

\begin{tabular}{|c|c|c|}
\hline Result & Condition indicator & Action \\
\hline \%deviation $<0.3$ & Good & \multirow[b]{2}{*}{ Normal condition, continue testing } \\
\hline $0.3 \leq \%$ deviation $<0.5$ & Fair & \\
\hline $0.5 \leq \%$ deviation $<0.7$ & Poor & \multirow{2}{*}{$\begin{array}{l}\text { Deviations at the tap positions within the same phase, } \\
\text { continue other tests to find the fault after repair } \\
\text { continue testing. }\end{array}$} \\
\hline$\%$ deviation $\geq 0.7$ & $\mathrm{Bad}$ & \\
\hline
\end{tabular}

$\%$ deviations $=\frac{T R_{M}-T R_{C}}{T R_{C}} \times 100 \%$

Table 3. The error in voltage ratio between the measured and calculated vratio

\begin{tabular}{lllll}
\hline Tap No & Phase R & Phase $\mathrm{Y}$ & Phase B & Condition \\
\hline 1 & 0.071 & 0.084 & 0.017 & good \\
2 & 0.031 & 0.042 & 0.029 & good \\
3 & 0.016 & 0.002 & 0.075 & good \\
4 & 0.063 & 0.051 & 0.093 & good \\
5 & 0.110 & 0.098 & 0.151 & good \\
\hline
\end{tabular}

\subsection{Frequency response analysis results}

The FRA test were performed on all three phases of the transformer. However, only results from RY phase is presented. This is because the other phases have similar result. Initially, the copper tapes are held on the tap changer using the G-clamp at very tight connection. The response is presented in Figure 5(a). It can be observed that there is a small variation at low frequency region at about $100 \mathrm{~Hz}$. It is also shown that there is a minor shifting towards higher frequencies as shown in Figure 5 inset. On the other hand, the frequency response for normal, pitting, and coking when the G-clamp is not very tight is shown in Figure 5(b). This is quite possible in real case where the springs to push taps in place has weaken. In the response, it can be observed that the negative slope from coking has a huge variation at low-frequency region at about $20 \mathrm{~Hz}$ to $2 \mathrm{kHz}$. This is where the influence of inductive element is observable. It could also be due to increasing of tap changer resistance. However, it could be seen a small variation between normal and pitting at about $100 \mathrm{~Hz}$.

Int J Pow Elec \& Dri Syst Vol. 11, No. 1, Mar 2020 : 350 - 358 

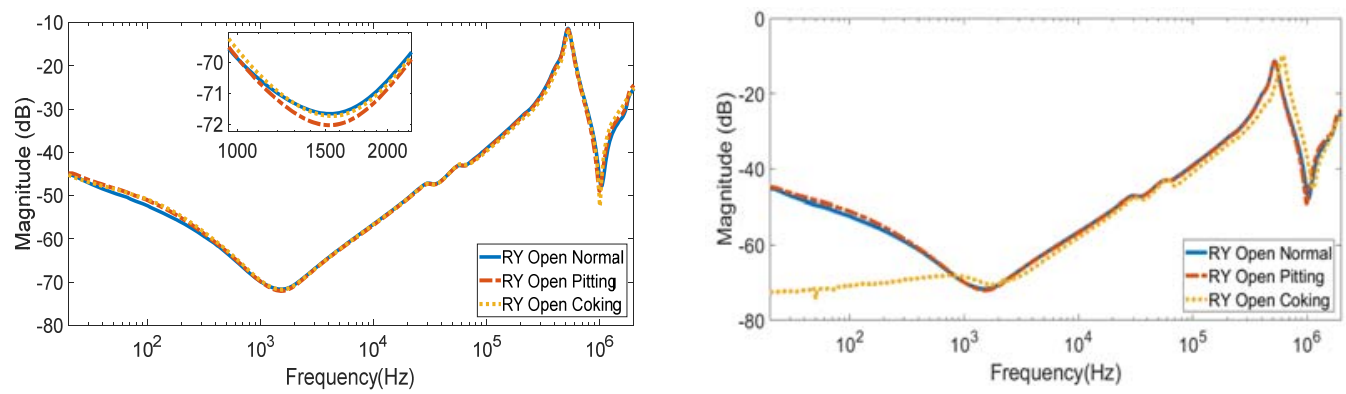

Figure 5. End to end open circuit response of RY phase at very tight taps (a) clamp is normal pressure (b) clamp is tight

Comparison between frequency responses of normal, pitting, and coking from the end to end short circuit test is shown in Figure 6(a). The response shows that pitting does not give any effect compare to the response of normal tap changer. However, frequency response due to coking shows a huge variation at lowfrequency region. Similar to end to end open and short circuit results, the inductive inter-winding test shows the variation due to coking of tap changer occurs at low-frequency region. The inductive inter-winding response is shown in Figure 6(b). Finally, the capacitive inter-winding test is unable to detect the tap changer faults. The frequency responses of normal, pitting, and coking at capacitive inter-winding measurement configuration is presented in Figure 6(c). No visible variation or changes between three responses.

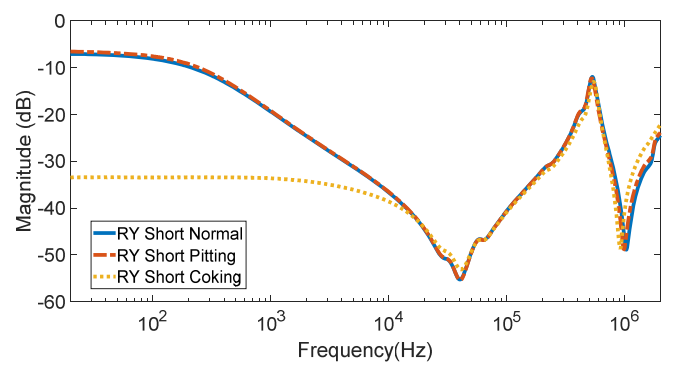

(a)

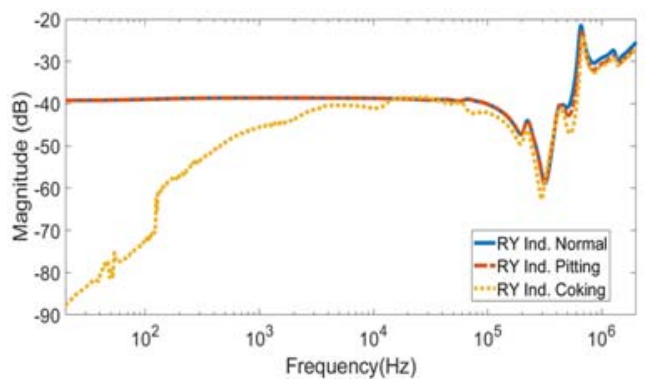

(b)

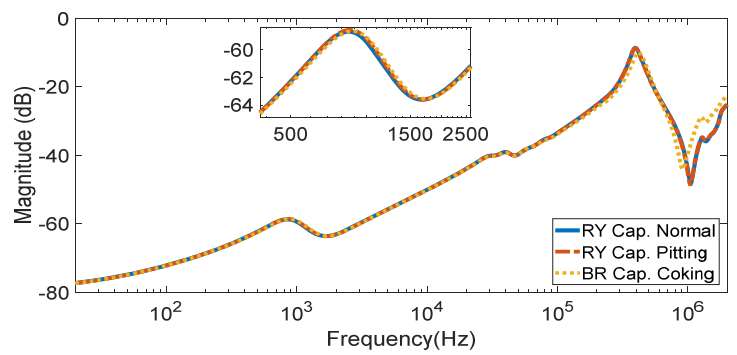

(c)

Figure 6. (a) End to end short circuit response of RY phase (b) Inductive inter-winding response of RY phase (c) Capacitive inter-winding response of RY phase

\subsection{Winding resistance results}

The winding resistance test has been conducted using transformer resistance meter model WRM-40 manufactured by Vanguard Instruments Co. The winding resistance measurement is presented in Table 4. In the normal tap changer, the maximum winding resistance is at phase $\mathrm{R}$ which is about $1.556 \mathrm{ohms}$. While the winding resistance of the tap changer due to pitting increased about $0.01 \mathrm{ohm}$ on all phases. However, the winding resistance increases at much higher value when the tap changer experience fault due to coking. The

Frequency response analysis for transformer tap changer damage detection (S. Al-Ameri) 
winding resistance at phase $\mathrm{R}$ shows $9.282 \mathrm{ohms}$ which is a huge value compare with normal at $1.556 \mathrm{ohms}$. Additionally, the cooking tap changer contact was damaged during the experiment. The damage was occurred during taking the measurement in phase B. For this reason, the resistance of phase B is $3.566 \mathrm{ohms}$ which is now smaller than resistance of phases $\mathrm{R}$ and $\mathrm{Y}$. To investigate the condition of transformer winding, the percentage difference of winding resistance between phases can be calculated using (3). Here $a$ and $b$ are the phases in transformer. The suggested actions based on the resistance are provided by local power utility as given in Table 5. The measured resistances are presented in Table 6 . The results suggest that all phases are in good condition at normal and pitting tap changer but in a bad condition when the tap changer has coking.

Table 4. Winding resistance of all phases at normal, pitting and coking of tap changer

\begin{tabular}{lllllllll}
\hline \multicolumn{2}{l}{$\operatorname{Normal}(\Omega)$} & \multicolumn{3}{l}{$\operatorname{Pitting}(\Omega)$} & \multicolumn{4}{l}{ Coking $(\Omega)$} \\
\hline $\mathrm{R}$ & $\mathrm{Y}$ & $\mathrm{B}$ & $\mathrm{R}$ & $\mathrm{Y}$ & $\mathrm{B}$ & $\mathrm{R}$ & $\mathrm{Y}$ & $\mathrm{B}$ \\
\hline 1.556 & 1.547 & 1.535 & 1.561 & 1.557 & 1.556 & 9.282 & 6.044 & 3.566 \\
\hline
\end{tabular}

Table 5. Results and actions for winding resistance test

\begin{tabular}{|c|c|c|}
\hline Result in ohms & Condition indicator & Action \\
\hline \%difference $<3$ & Good & \\
\hline $3 \leq \%$ difference $<5$ & Fair & Normal condition, contınue testing \\
\hline $5 \leq \%$ difference $<7$ & Poor & \multirow{2}{*}{$\begin{array}{l}\text { Deviations at the tap positions within the same phase, } \\
\text { continue other tests to find the fault after repair } \\
\text { continue testing. }\end{array}$} \\
\hline$\%$ difference $\geq 7$ & Bad & \\
\hline
\end{tabular}

$$
\% \Delta \Omega=\frac{\Omega_{a}-\Omega_{b}}{\Omega_{b}} \times 100 \%
$$

Table 6. The percentage difference of resistance between phases

\begin{tabular}{lllll}
\hline Tap condition & $\begin{array}{l}\text { Phases } \\
\text { (R vs. Y) }\end{array}$ & $\begin{array}{l}\text { Phases } \\
\text { (Y vs. B) }\end{array}$ & $\begin{array}{l}\text { Phases } \\
\text { (B vs. R) }\end{array}$ & State \\
\hline Normal & 0.582 & 0.782 & 1.368 & Good \\
Pitting & 0.257 & 0.064 & 0.321 & Good \\
Coking & 53.574 & 69.490 & 160.292 & Bad \\
\hline
\end{tabular}

\section{CONCLUSION}

FRA test is a recognized method to detect the transformer winding faults. In this paper, the FRA is used to investigate normal and faulty transformer tap changer. Three tap changer conditions were formed and observe the winding frequency response of four test configurations. This gives a clear understanding of the capability of using FRA to detect the transformer tap changer faults. The results show that end to end open circuit, end to end short circuit, inductive inter-winding tests are sensitive to tap changer coking at the negative slope in the low-frequency region. On the other hand, pitting on tap contact has a small effect on the FRA at all frequency region. The turn ratio measurement is to identify the taps positions. It also verifies that the all phases $V_{\text {ratio }}$ are in good condition. In addition, the winding resistance measurement is conducted to validate the FRA findings. It is founded that, pitting in the transformer tap contact slightly increase the winding resistance. However, coking on tap changer contact has more effect on the winding resistance than pitting. The winding resistance increases from $1.556 \mathrm{ohms}$ at normal tap changer to 9.252 ohms due to coking on tap changer contact. Eventually, the FRA is a sensitive tool can be utilized to detect tap changer coking and pitting. Further study is recommended to investigate other expected transformer tap changer faults using FRA.

\section{ACKNOWLEDGEMENTS}

The authors would like to thank the TNB Research for the provision of test facilities and great support for the experimental tests. This work is supported financially by the Islamic University, Iraq research grant PRG-IUNAJAF-2019.

Int J Pow Elec \& Dri Syst Vol. 11, No. 1, Mar 2020 : 350 - 358 


\section{REFERENCES}

[1] E. G. R. Jongen, P. Morshuis, J. Smit, A. Janssen, "A statistical approach to processing power transformer failure data," 19th Int. Conf. Electr. Distrib, no. Vienna, 0736, pp. 21-24, 2007.

[2] J. J. Erbrink, E. Gulski, J. J. Smit, P. P. Seitz, and R. Leich, "Experimental model of aging mechanisms of on-load tap changer contacts," in International Conference on Condition Monitoring and Diagnosis, pp. 247-250, 2007.

[3] N. Cincar and G. Milojevic, "On-load tap changer testing methods," vol. 8, no. support@dv-power.com., pp. 1-8, 1991.

[4] J. Erbrink, J. Smit, E. Gulski, and R. Leich, "Experimental model for diagnosing on-load tap changer contact aging with dynamic resistance measurements," in 20th International Conference and Exhibition onElectricity Distribution, pp. 1-4, 2009.

[5] S. Charles, G. Wenyu, and R. Ulmer, "Diagnostic testing and monitoring of power transformers, Know the condition of your transformer," OMICRON, vol. L2673, pp. 1-36, 2016.

[6] A. A. Salem et al., "The effect of insulator geometrical profile on electric field distributions," Indones. J. Electr. Eng. Comput. Sci., vol. 14, no. 2, pp. 618, 2019.

[7] Cigre WG A2.26, "Mechanical condition assessment of transformer windings using frequency response analysis (Fra)," Cigre, pp. 30-34, 2008.

[8] "IEEE guide for the application and interpretation of frequency response analysis for oil-immersed transformers IEEE power and energy society," IEEE Std C57.149-2012, pp. 1-72, 2013.

[9] M. F. M. Yousof, C. Ekanayake, and T. K. Saha, "An investigation on the influence of tap changer on frequency response analysis," in IEEE 11th International Conference on the Properties and Applications of Dielectric Materials (ICPADM) an, pp. 963-966, 2015.

[10] S. Banaszak and W. Szoka, "Influence of a tap changer position on the transformer's frequency response," in Innovative Materials and Technologies in Electrical Engineering (i-MITEL), pp. 18-21, 2018.

[11] S. Al-Ameri, M. F. M. Yousof, H. Ahmad, M. Alsubari, and M. A. Talib, "Examining faulty transformer tap changer using frequency response analysis," in 2017 International Symposium on Electrical Insulating materials (ISEIM), pp. 259-262, 2017.

[12] M. Bagheri, M. S. Naderi, T. Blackburn, B. T. Phung, and Z. Liu, "Frequency response analysis to recognize inductance variation in transformer due to internal short circuit," 10th Int. Power Energy Conf. IPEC 2012, pp. 677-681, 2012.

[13] J. C. G. Arispe and E. E. Mombello, "Detection of failures within transformers by FRA using multiresolution decomposition," IEEE Trans. Power Deliv., vol. 29, no. 3, pp. 1127-1137, 2014.

[14] S. Al-Ameri, M. F. M. Yousof, N. Azis, S. Avinash, M. A. Talib, and A. A. Salem, "Modeling frequency response of transformer winding to investigate the influence of RLC," Indones. J. Electr. Eng. Comput. Sci., vol. 14, no. 1, pp. 219-229, 2019.

[15] P. Picher, "Mechanical condition assessment of transformer windings using frequency response analysis (Fra)," Cigre, Evaluation, vol. A2.26, pp. 30-34, 2008.

[16] O. Predl, Florian, "Interpretation of sweep frequency response analysis (SFRA) measurement results," OMICRON energy, pp. 1-26, Australia 2016.

[17] G. Kennedy, A. McGrail, and J. Lapworth, "Transformer sweep frequency response analysis (SFRA)," Energize, eepublishers, pp. 1-12, 2007.

[18] A. Islam, "Detection of mechanical deformation in old aged power transformer using cross correlation co-efficient analysis method," Energy Power Eng., vol. 03, pp. 585-591, Sep 2011.

[19] A. S. Murthy, N. Azis, S. Al-Ameri, M. F. M. Yousof, J. Jasni, and M. A. Talib, "Investigation of the effect of winding clamping structure on frequency response signature of $11 \mathrm{kV}$ distribution transformer," Energies, vol. 11, no. 9, pp. 1-13, 2018.

[20] V. Behjat and M. Mahvi, "Statistical approach for interpretation of power transformers frequency response analysis results," IET Sci. Meas. Technol., vol. 9, no. 3, pp. 367-375, 2015.

[21] Y. Liu, Z. Wang, and P. J. Griffin, "Artificial intelligence in OLTC fault diagnosis using dissolved gas-in-oil information," in Power Engineering Society Summer Meeting (Cat. No.00CH37134), pp. 193-211, 2000.

[22] J. Hillergren and M. Lindahl, "On moving contacts in on-load tap changers," Master Sci. Thesis, no. Chalmers University of Technology ABB Components G" oteborg, Sweden, 2010.

[23] J. J. Smit, "On-load tap changer diagnosis on high-voltage power transformers using dynamic resistance measurements," Technische Universiteit Delft, College voor Promoties, 2011.

[24] IEC 60076-18 Ed.1, "Power transformers - Part 18, 'Measurement of frequency response'," 2012.

[25] Doble Vanguard, "Winding resistance ohmmeter, WRM-40 | Vanguard Instruments Company, Inc.," 2009. [Online]. Available: https://www.vanguard-instruments.com/categories/transformer-winding-resistancemeters/wrm-40. [Accessed: 13-Dec-2018]. 


\section{BIOGRAPHIES OF AUTHORS}
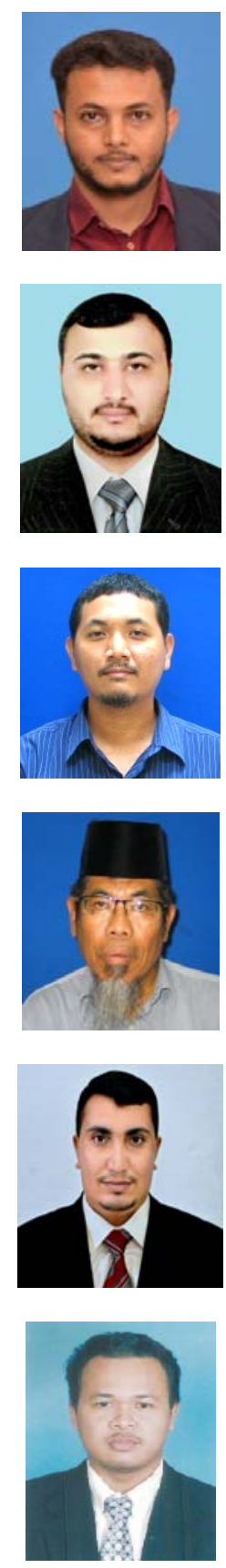

Salem Mgammal Awadh Nasser Al-Ameri received B.Eng. in Mechatronics Engineering from Asia Pacific University (APU) in 2012. He received M.Eng. in Electrical Power from Universiti Tun Hussein Onn Malaysia (UTHM) from 2014 to 2016. Currently he is pursuing Ph.D. Degree in Universiti Tun Hussein Onn Malaysia. His research is on transformer condition monitoring using FRA.

Ahmed Allawy Mohammed Alawady received B.Eng. in Electrical from University of Kufa, Iraq in 2007. He received M.Eng. in Electrical power system from (SHUATS), India in 2012. He is a lecturer at the Department of Computer Technical Engineering, Collage of Technical Engineering at Islamic University, Iraq since 2007. Currently he is pursuing Ph.D. Degree in Universiti Tun Hussein Onn Malaysia. His research is on motors faults detection using FRA.

Mohd Fairouz Mohd Yousof received B.Eng. (Electrical) and M.Eng. (Electrical) both from Universiti Teknologi Malaysia (UTM) in 2008 and 2010, respectively. He is a lecturer at the Department of Electrical Power Engineering at Universiti Tun Hussein Onn Malaysia since 2009. He received Ph.D. degree from The University of Queensland, Australia in 2015. Currently he is on industrial attachment with Tenaga Nasional Berhad Research involving many research projects especially on condition monitoring of transformer.

Hussein Ahmad was born in Mersing, Johor, Malaysia. He obtained his B.Sc (Hons) and M.Sc in Electrical Engineering from the University of Strathclyde, Scotland, UK in 1977 and 1981, respectively and subsequently obtained his $\mathrm{PhD}$ degree in high voltage engineering from University of Manchester (formerly UMIST) in 1986. Currently, he is a professor in the faculty of Electrical Engineering, in Universiti Tun Hussein Onn Malaysia. His research interests include lightning protection, grounding system, low voltage protection, and insulation performance.

Ali Ahmed Ali Salem (Ali. A. Salem) was born in Sana'a, Yemen on March 1, 1985. He received M.Eng. in Electrical Power Engineering from Universiti Tun Hussein Onn Malaysia (UTHM) from 2014 to 2016. Currently he is Pursuing Ph.D. degree at High Voltage in Faculty of Electrical Engineering, UTHM. His research interest includes the dynamic arc modelling of pollution flashover on high voltage outdoor insulators

Mohd Aizam Talib received his Bachelor in Electrical Engineering from the University of Portsmouth, UK in 1997, and Master degree in Electrical Engineering from Universiti Tenaga Nasional (UNITEN), Malaysia in 2001. Upon graduation in 1997, he worked with ABB Transmission and Distribution Sdn Bhd as a Design Engineer. Since 1998, he has been employed by TNB Research Sdn Bhd as a Research Engineer. His research interests are in transformer condition monitoring, insulation diagnostic and dielectric measurements. He is currently a Ph.D. degree student at Universiti Teknologi Malaysia. 